\title{
Reflexões sobre a ação pedagógica no desenvolvimento da modelagem matemática
}

\author{
Action teaching in the development of Mathematical Modeling
}

\author{
Luzinete de Oliveira Mendonça ${ }^{1}$ \\ Celi Espasandin Lopes ${ }^{2}$
}

\begin{abstract}
Resumo
Este trabalho buscou ampliar compreensões acerca da ação pedagógica em ambientes de aprendizagem na perspectiva de modelagem matemática. Para isso, realizou-se uma pesquisa de natureza qualitativa. Tomaramse, como objeto de análise, as ações e os diálogos realizados em um contexto específico de ensino e aprendizagem entre uma professora e seus alunos de uma turma de quinto ano de uma escola municipal. A pesquisa possibilitou observar que, no desenvolvimento da tarefa de modelagem, a intervenção pedagógica variou de acordo com as necessidades dos estudantes e os objetivos da atividade. Essa constatação leva à conclusão de que a mudança de atitude do docente no decorrer do processo é decorrente da natureza dinâmica da investigação na perspectiva da modelagem matemática, a qual exige diferentes graus de intervenções, de modo a contribuir para o desenvolvimento de conceitos, atitudes e raciocínios específicos, levando em conta a autonomia para a construção de conhecimentos pelos estudantes.
\end{abstract}

Palavras-chave: intervenção pedagógica; modelagem matemática; Educação Estatística; autonomia.

\begin{abstract}
This work aimed to expand the understanding of the pedagogical action, in learning environments, under the perspective of mathematical modeling. In order to do so, a qualitative research study was carried. The object of analysis was the actions and dialogues, occurring in a specific teaching and learning context, between a teacher and her $5^{\text {th }}$-grade students, in a public elementary school. The research allowed us to observe that during the modeling task, the pedagogical intervention varied according to the needs of the students and the goals of the activity. This finding leads to the conclusion that the change in teacher's attitude during the process is due to the dynamic nature of the investigation from a mathematical modeling perspective, which requires different levels of intervention, in order to contribute to the development of concepts, attitudes and specific reasoning, taking into account the role of autonomy in the construction of knowledge by students.
\end{abstract}

Keywords: pedagogical intervention; mathematical modeling; Statistics education; autonomy.

\section{Introdução}

A sala de aula é um contexto complexo, no qual estão envolvidos diversos interesses, sentimentos e objetivos. Nesse cenário, o professor, mentor e articulador do ambiente de

\footnotetext{
${ }^{1}$ Doutora em Ensino de Ciências e Matemática. Grupo de Investigação e Formação em Educação Matemática Universidade Cruzeiro do Sul, Brasil. Email: luza.oliveira7@gmail.com.

${ }^{2}$ Doutora em Educação. Professora titular na Universidade Cruzeiro do Sul/UNICSUL Brasil. Email: celi.espasandin.lopes@gmail.com.
}

Zetetiké, Campinas, SP, v.25, n.2, maio/ago.2017, p.305-323. 
DOI: http://dx.doi.org/10.20396/zet.v25i2.8648493

aprendizagem, constantemente se vê às voltas com situações em que precisa se posicionar, direcionar, instigar e envolver (Arnaus, 1999).

A rotina do professor demanda um processo contínuo de busca por conhecimentos conceituais, metodológicos e pedagógicos, em que a reflexão sobre sua prática é fundamental. Esse processo, a nosso ver, se constitui em um importante meio de formação profissional, o qual pode ser potencializado quando os docentes têm oportunidades de socializar e discutir com os pares acerca da problemática que envolve sua prática.

A discussão sobre a formação contínua interessa a este trabalho, porque a formação inicial do professor de Matemática no Brasil destina poucas oportunidades para o aprofundamento das questões didáticas e metodológicas, particularmente no que se refere à Educação Estatística. Além disso, conforme Biembengut e Vieira (2013), há um "descompasso" entre as Orientações Curriculares da Educação Básica e a formação do professor, e essas questões se repetem no cenário internacional.

Essa situação é ainda mais preocupante em relação aos cursos de Pedagogia, que formam o professor polivalente ${ }^{3}$, pois, conforme Libâneo (2010), eles não contemplam muitos dos conhecimentos específicos que os professores precisarão ensinar. No que se refere à Educação Estatística, essa condição se amplia, em função de serem desconhecidos, para muitos desses docentes, os conceitos e os raciocínios inerentes a essa área. Tal circunstância reflete o desacordo entre aquilo que o professor precisa ensinar e o que pôde acessar em sua formação profissional inicial. Esse entendimento é ratificado por resultados de estudos empíricos que mostram dificuldades, de diversas naturezas, de professores especialistas e generalistas, no que se refere a ideias e conceitos estatísticos (Arteaga, Batanero, Cañadas \& Contreras, 2009; Batanero, 2009).

Temos observado consenso em torno da ideia de que a abordagem da Educação Estatística deve ocorrer a partir de uma perspectiva investigativa em processos de análise de dados reais (Lopes, 2003; Mendonça, 2008). Essa dinâmica favorece o desenvolvimento do raciocínio estatístico, necessário à compreensão dos fenômenos aleatórios com os quais a Estatística lida (Wild \& Pfannkuch, 1999).

Apesar dessa evidência, estudos mostram que o trabalho com dados reais, bem como com atividades investigativas, não é tarefa fácil para muitos professores (Batanero, 2009; Chick \& Pierce, 2010), apesar do forte movimento nesse sentido, como se observa nas diversas abordagens da inquiry-based education ${ }^{4}$. A modelagem matemática, uma dessas abordagens, tem sido defendida por diversos professores e pesquisadores, que a tomam como uma possibilidade relevante para a construção do conhecimento matemático dos alunos. Concordamos com essa defesa e consideramos que esta perspectiva pedagógica é convergente com a Educação Estatística, em função de sua característica investigativa.

\footnotetext{
${ }^{3}$ Esses professores atuam na Educação Infantil e nos anos iniciais do Ensino Fundamental (1. ${ }^{\circ}$ ao 5. ${ }^{\circ}$ ano).

${ }^{4}$ Educação baseada na inquirição.
} 
DOI: http://dx.doi.org/10.20396/zet.v25i2.8648493

Entretanto, vemos a necessidade de esclarecimentos sobre a dinâmica da sala de aula no desenvolvimento de atividades nessa perspectiva.

A falta de clareza sobre a dinâmica característica das atividades de modelagem matemática ${ }^{5}$ talvez seja o motivo de ser, ainda hoje, incipiente sua concretização nas salas de aula, como observam Blum e Ferri (2009) e Silva e Dalto (2011). Ao buscar os motivos que levam professores favoráveis à modelagem a não a adotarem em sua rotina de trabalho, Barbosa (2004) faz um levantamento de estudos que tratam desse tema e apresenta três aspectos recorrentes:

- falta de clareza sobre a operacionalização dessas atividades no contexto escolar, onde, em geral, predominam programas pré-estabelecidos e cujas rotinas já estão estabelecidas;

- dúvidas sobre os conhecimentos dos professores para conduzir as atividades;

- não se sabe como os alunos, colegas de trabalho, coordenadores e pais reagirão à proposta. (p. 5)

Os fatores apresentados evidenciam que o currículo escolar pode ser uma barreira para a adoção da modelagem na prática docente, pois há preocupação dos docentes com sua aceitação pela comunidade escolar e pela família dos alunos. Ponderamos que ampliar as discussões sobre a ação pedagógica com base nessa perspectiva pode contribuir para amenizar esses aspectos.

Desse modo, interessa-nos aqui discutir algumas questões relativas ao fazer modelagem na sala de aula, com especial atenção às relações entre a ação pedagógica e o processo de construção dos alunos. Para isso, tomamos alguns episódios ocorridos no desenvolvimento de um projeto elaborado por uma professora participante de um grupo de natureza colaborativa, a partir da perspectiva de modelagem. Os diálogos ocorridos na ação empreendida, nossa observação e os modelos construídos pelos alunos, constituem-se em objetos de análises e discussões.

Inicialmente descrevemos a metodologia de pesquisa e caracterizamos o contexto observado. Posteriormente, relatamos e analisamos um episódio em que a professora e seus alunos fizeram a análise de um modelo matemático construído por um grupo para apresentar os resultados de sua investigação. A partir da interação observada no recorte do diálogo e da recorrência a outros momentos no decorrer do projeto, refletimos sobre a intervenção pedagógica, com vistas a construir compreensões sobre a forma como essa se efetivou no decorrer do processo.

\section{Metodologia}

Esta é uma pesquisa de natureza qualitativa, levando em conta os pressupostos de Garnica (2004). A opção por essa abordagem decorre da priorização dos procedimentos descritivos e da assunção da inferência subjetiva dos pesquisadores, particularmente por eles

\footnotetext{
${ }^{5}$ A partir desse ponto, por vezes, usaremos o termo "modelagem" no sentido de "modelagem matemática", para evitar repetições.
} 
DOl: http://dx.doi.org/10.20396/zet.v25i2.8648493

se inserirem no contexto pesquisado. Com isso, a pesquisa efetivada configura-se como um estudo de caso, em função de sua especificidade e de seu nível de detalhamento.

Este trabalho é uma releitura de parte de uma pesquisa de doutorado, Mendonça (2015), que buscou compreender o envolvimento de professores participantes de um grupo de natureza colaborativa, em um ambiente de discussões e ações referentes à modelagem para a efetivação da Educação Estatística na sala de aula do Ensino Básico.

Durante o período de construção dos dados, foram proporcionadas cinco ações consideradas relevantes, na literatura, para a formação de juízo acerca dessa abordagem, a saber: vivência em atividades de modelagem, reflexão sobre casos de ensino, análise de modelos matemáticos prontos, elaboração de atividades e intervenções em sala de aula em atividades na perspectiva de modelagem (Barbosa, 2001; Bassanezi, 2004; Chaves, 2012). As ações apresentadas foram vivenciadas com apoio de textos teóricos e casos de ensino, além de práticas dos professores, o que gerou discussões pautadas na reflexão sobre questões conceituais, metodológicas e pedagógicas inerentes à modelagem.

Neste trabalho nos limitamos a discutir a ação intervenção pedagógica em atividades de modelagem. Essa escolha decorreu da necessidade de detalhamento da discussão, o que inviabiliza a abrangência de todas as vivências. Analisamos, mais adiante, um episódio de sala de aula de um projeto desenvolvido por uma das professoras do grupo.

\section{A construção dos dados}

A pesquisa se estabeleceu a partir de um grupo de natureza colaborativa que discute a Educação Estatística em encontros quinzenais, GIFEM $^{6}$. Durante a construção dos dados, o grupo contava com cinco professores da Educação Básica (quatro especialistas e uma pedagoga), além das duas autoras deste texto.

A proposta de trabalho que será analisada foi realizada pela professora aqui denominada "Silvia". Formada em Pedagogia, tinha sete anos de magistério na época e trabalhava na rede municipal da Cidade de Campinas-SP. A ação pedagógica analisada foi elaborada com uma turma de quinto ano do Ensino Fundamental, com 20 alunos, em uma escola pública municipal. A docente propôs desenvolver um projeto no qual os estudantes vivenciassem as etapas de uma investigação estatística, na perspectiva de Mendonça (2008), para a abordagem da Educação Estatística em ambientes de modelagem. Os alunos deveriam participar das seguintes etapas: escolha do tema, elaboração do instrumento de coleta de dados, pesquisa de campo, análise dos dados e comunicação dos resultados.

Constituíram-se em dados empíricos para este estudo os diálogos ${ }^{7}$ entre a professora e seus alunos no momento em que os estudantes socializaram os resultados de suas pesquisas. A implementação da atividade foi gravada em vídeo. Além disso, os episódios apresentados

\footnotetext{
${ }^{6}$ Grupo de investigação e formação em Educação Matemática.

${ }^{7}$ Os nomes apresentados nos diálogos são fictícios, para preservar a identidade da professora e dos alunos.
} 
DOl: http://dx.doi.org/10.20396/zet.v25i2.8648493

foram observados, discutidos no grupo e, posteriormente, transcritos, na tentativa de buscar compreensão sobre o delineamento do processo empreendido, com especial atenção à intervenção pedagógica e a sua influência na construção do conhecimento pelos alunos.

Para esta análise, apoiar-nos-emos na noção de percurso discursivo de Barbosa (2006, 2007) e na proposta de Blum e Ferri (2009) sobre os diferentes tipos de intervenção pedagógica no desenvolvimento de atividades de modelagem. Temos como base também outros pressupostos teóricos, que apresentaremos em seguida.

\section{Referencial teórico}

A intervenção pedagógica no desenvolvimento de atividades de modelagem ainda está cercada de dúvidas e inseguranças e envolve diversos aspectos. São comuns, por exemplo, questionamentos como: Se eu sistematizar um conceito no decorrer do processo, estou conduzindo demais? Sem essa intervenção o grupo vai evoluir na construção dos conceitos e dos procedimentos? Essas e tantas outras questões são decorrentes da complexa rede de interesses que envolve o ensino de forma geral e a sala de aula em particular. Esse fator exerce poder sobre as ações do professor, limitando-o em vários sentidos, conforme assegura Arnaus (1999). No entanto, essas questões também estão ligadas à complexidade da própria atividade de modelagem e à falta de clareza no desenvolvimento desse processo, particularmente em função de sua natureza aberta e interdisciplinar.

Apesar disso, a modelagem tem sido considerada uma possibilidade relevante de construção do conhecimento matemático por diversos documentos de orientações curriculares; por pesquisadores, no âmbito nacional e internacional; e por professores que atuam nos diferentes níveis de ensino (Barbosa, 2001, 2004; Blum \& Ferri, 2009; Mendonça, 2008, 2015). Apesar disso, Oliveira (2010) pondera que a prática pedagógica com modelagem matemática implica em algumas tensões e dilemas. Em Mendonça e Lopes (2011a) também é possível observar indícios dessa ideia na reflexão de uma professora sobre a própria experiência com a modelagem. No que se refere às ações da prática pedagógica - as quais são de interesse deste estudo -, sua pesquisa mostra que o professor, no desenvolvimento das atividades de modelagem, as recontextualiza, atribuindo-lhes significado próprio. A autora considera, no entanto, que esse não é um processo simples, em função das vivências anteriores com outras formas de ações pedagógicas já consolidadas.

As discussões sobre o trabalho com a modelagem na sala de aula e diversos outros aspectos que envolvem essa prática - a insegurança do professor em relação aos questionamentos dos alunos, a apatia ou a recusa desses no desenvolvimento do processo e as dúvidas sobre o momento adequado para sistematizar conceitos - ocorrem, conforme sustentam Blum e Ferri (2009), porque a modelagem também não é fácil para o professor.

Tais considerações indicam a necessidade de promover ambientes que levem os professores a vivenciar a prática de modelagem e a refletir sobre esse processo. Além disso, é significativa a reflexão sobre a influência da intervenção pedagógica no decorrer do desenvolvimento de atividades pelos alunos, pois esse aspecto ainda não está esclarecido no meio acadêmico, o que pode gerar equívocos por excesso (o professor direciona 
DOI: http://dx.doi.org/10.20396/zet.v25i2.8648493

exageradamente o trabalho dos alunos) ou por falta (os alunos são levados a trabalhar sozinhos, com a proposta de desenvolver a autonomia).

Tomemos para reflexão duas propostas de intervenção em atividades de modelagem. Elas têm bases epistemológicas diferentes, no que se refere ao foco e aos objetivos da modelagem. Estamo-nos referindo à proposta de Blum e Ferri (2009), a qual se embasa nos aspectos cognitivos presentes no processo de modelagem, e ao constructo do "percurso discursivo”, de Barbosa (2006), que se encaminha pelos discursos produzidos no decorrer do processo investigativo dos alunos.

\section{A intervenção pedagógica no desenvolvimento de atividades de modelagem}

Blum e Ferri (2009) e Ferri (2008) consideram que a intervenção pedagógica no desenvolvimento de atividades de modelagem requer alguns conhecimentos específicos dessa opção metodológica. Um desses saberes é a "clareza sobre ciclo de modelagem ${ }^{8}$. Na perspectiva dos autores, esse conhecimento possibilita fazer diagnósticos adequados das necessidades dos alunos, o que permite uma intervenção apropriada para ajudá-los a evoluir de uma etapa para outra.

Blum e Ferri (2009) pontuam também a necessidade do "conhecimento dos estilos de pensamento matemático dos alunos". Essa proposta considera importante que os diferentes modos de pensar a matemática sejam conhecidos pelo professor, para que, a partir deles, ele possa intervir para estimular a evolução dos estudantes no processo de modelagem. São três os estilos de pensamento: visual, analítico e integrado. As pessoas que possuem pensamento visual raciocinam por imagens mentais e representações externalizadas, têm uma visão geral sobre as situações-problemas e concentram-se mais na parte do mundo real, em um processo de modelagem, enquanto as que têm estilo analítico preferem fazer cálculos mentais, são capazes de entender e expressar fatos matemáticos de modo simbólico ou verbal e têm preferência por processos passo a passo para resolver os problemas. Estas, no desenvolvimento das tarefas de modelagem, costumam focar mais na parte matemática do problema. Por fim, as pessoas com pensamento integrado são capazes de transitar pelos dois estilos de pensamentos descritos (Blum \& Ferri, 2009).

O conhecimento do modo de pensar do aluno é importante para que o professor compreenda respostas e procedimentos adotados por ele e, assim, elabore sua estratégia de ação para intervir de forma produtiva. Ademais, Blum e Ferri (2009) expressam a importância do conhecimento do próprio estilo de pensamento matemático. Esse fator ajuda o professor a encontrar o equilíbrio, a pensar e a agir, ao lidar com a Matemática, além de

\footnotetext{
${ }^{8} \mathrm{O}$ ciclo de modelagem, conforme Ferri (2006), compreende as seguintes etapas: a compreensão da situaçãoproblema, a simplificação dessa situação e sua matematização, além da elaboração do modelo genérico, da interpretação do modelo matemático obtido com relação à situação inicial e de sua validação. Ainda que diversas maneiras de ver o processo de modelagem sejam concebidas, de forma geral, o desenvolvimento de uma atividade de modelagem inclui compreensão da situação, simplificação, problematização, matematização, interpretação, validação e comunicação. O que tem semelhanças com o ciclo de modelagem proposto por Ferri (2006).
}

Zetetiké, Campinas, SP, v.25, n.2, maio/ago.2017, p.305-323.

ISSN 2176-1744 
DOl: http://dx.doi.org/10.20396/zet.v25i2.8648493

auxiliá-lo na comunicação e na compreensão de estilos de pensamento matemático de seus alunos, o que, conforme os autores, permite ao docente atentar para não impor seu próprio estilo e desvalorizar os dos alunos.

Os autores também afirmam que é significativo possuir conhecimento dos diversos estilos de intervenção, para lidar com as diferentes situações de ensino com tarefas de modelagem. Consideram ainda a necessidade de consciência do estilo de intervenção preferido para encontrar equilíbrio entre sua intervenção e a independência dos alunos. Nesse sentido, Blum e Ferri (2009) salientam:

Para um ensino de qualidade, é fundamental que um equilíbrio permanente entre a orientação (mínima) do professor e a independência (máxima) dos alunos seja mantido, de acordo com a célebre máxima de Maria Montessori: "Ajuda-me a fazer isso por mim". Em particular, quando alunos estão lidando com tarefas de modelagem, esse equilíbrio é melhor alcançado adequando a intervenção do professor para preservar a independência dos alunos. Nesse contexto, intervenções estratégicas são as mais adequadas, o que muitas vezes significa fazer intervenções que dão dicas para os estudantes em um meta-nível. [tradução nossa, grifos dos autores] (p. 52)

Nessa concepção, a intervenção no desenvolvimento da modelagem na sala de aula deve provocar os alunos para evoluir rumo aos objetivos da atividade proposta, o que pode ser feito por meio de dicas como: "Imagine a situação! o que você visa? o que você tem? o que ainda está faltando? será que esse resultado se encaixa com a situação real? " [tradução nossa] (Blum \& Ferri, 2009, p. 52). Esse processo está relacionado à necessidade de uma problematização, pelo professor, da situação investigada pelos alunos no decorrer do processo, de forma a criar condições para eles desenvolverem raciocínios específicos, sem, no entanto, direcioná-los. Conforme Mendonça (1993), esse é o caminho para se fazer modelagem na sala de aula na Educação Básica. Nessa perspectiva, problematização "é o caminho para chegar ao problema, que se formulado, pode desencadear, na solução, a construção de conhecimentos matemáticos” (p. 274). É possível inferir que, vivenciando o desenvolvimento de atividades dessa natureza, o professor constrói o repertório de possibilidades de intervenção em cada situação nova que surge.

Enquanto, na perspectiva de Blum e Ferri (2009), a intervenção no desenvolvimento de atividades de modelagem é orientada pelos estilos de pensamento dos alunos e dos professores e pelos estilos de intervenção destes, Barbosa (2006, 2007) adota como orientação para a intervenção os "percursos discursivos" presentes no ambiente de aprendizagem. Desse ponto de vista, os discursos legitimam as ações dos alunos e sua observação é essencial para a compreensão do processo empreendido por eles no espaço de interação promovido no desenvolvimento da investigação (Barbosa, 2007). Um "percurso discursivo”, para Barbosa e Santos (2007, p. 5) é "uma progressão dos discursos produzidos pelos alunos e/ou professor no ambiente social". Essa visão está pautada na abordagem de Skovsmose (1990) sobre a natureza do processo de Modelagem em termos de conhecimento matemático, técnico e reflexivo. Barbosa (2006), em um processo análogo, define modelagem matemática a partir das práticas discursivas. As discussões dos alunos durante o desenvolvimento de uma tarefa de modelagem, de acordo com Barbosa e Santos (2007), podem ser:

Zetetiké, Campinas, SP, v.25, n.2, maio/ago.2017, p.305-323.

ISSN 2176-1744 
DOI: http://dx.doi.org/10.20396/zet.v25i2.8648493

- matemáticas: referem-se às ideias pertencentes ao campo da matemática pura.

- técnicas: referem-se à construção do modelo matemático, em particular à transição da situação para a representação matemática;

- reflexivas: referem-se à natureza do modelo matemático, aos critérios utilizados em sua construção e suas consequências. (p. 5)

Os autores consideram que o foco da perspectiva sociocrítica de modelagem está nas discussões reflexivas; no entanto, as discussões matemáticas e técnicas lhes dão suporte.

É possível ponderar que a observação das discussões nos grupos dá indicações do envolvimento dos alunos com o trabalho, de sua evolução e de suas necessidades. Nesse sentido, Barbosa (2006) esclarece:

A possibilidade de constituir atividades de modelagem na perspectiva sociocrítica está associada à presença das discussões reflexivas. É difícil imaginar esta perspectiva operando em sala de aula sem que questões dessa natureza estejam presentes. Porém, não me refiro à mera figuração nos espaços de interações; essas discussões devem ter um lugar primário, usando as demais para apoiá-la. (p. 9)

Os autores chamam a atenção para o foco da perspectiva sociocrítica ${ }^{9}$. No entanto, é pertinente considerar que os três tipos de discussões permeiam o desenvolvimento das atividades de modelagem em todas as perspectivas presentes na Educação Matemática, elencadas por Kaiser e Sriraman (2006). Por exemplo, na perspectiva cognitiva de modelagem, as discussões técnicas são o foco de interesse, já que, nessa ótica, o processo se centra no desenvolvimento da competência de modelagem em si, enquanto a perspectiva epistemológica se atém às discussões matemáticas, pois seu interesse é a construção do modelo matemático ou a teoria matemática. Ainda assim, as discussões reflexivas podem ser provocadas pelo professor. Enfim, é notório que os registros produzidos pelos alunos, assim como as discussões presentes na interação entre eles e o professor, constituem-se em importantes meios para a implementação de um ambiente produtivo para a formação matemática dos alunos. Essa interação, a nosso ver, pode fornecer elementos para análise da natureza da ação pedagógica que ali se desenvolve. Para isso, nos valemos da compreensão de Zaslavsky (2017) de que a ação pedagógica "é a coordenação entre ação docente e ação discente. Pode-se dizer que a ação pedagógica é, mais propriamente, uma interação pedagógica. Discentes e docentes, orientados à aprendizagem, podem valer-se de meios reflexivos, no caso, argumentativos e não instrumentais" (p. 77). A ação pedagógica tem, portanto, o diálogo como um elemento mediador para a constituição de um espaço democrático e reflexivo, conforme assinala Síveres (2016):

A palavra dia-logos tem na sua raiz grega uma conexão entre o discurso e a prática, uma vinculação entre o pensamento e o sentimento, e uma interação entre a razão e a experiência. Neste sentido o diálogo não é apenas uma cadeia produtiva de informações, nem uma rede de comunicações e, nem tampouco, um sistema de tecnologias de comunicação. Mesmo contando com estas instrumentalidades, o

\footnotetext{
${ }^{9}$ A perspectiva sociocrítica tem como principal objetivo pedagógico a compreensão crítica do mundo. Nesse entendimento, o conhecimento dos objetos e dos conceitos da Matemática tem papel importante, pois esta embasa as Ciências de modo geral.
} 
DOI: http://dx.doi.org/10.20396/zet.v25i2.8648493

diálogo é um princípio instituidor da existência humana, uma mediação para a construção do conhecimento e, portanto, uma possibilidade de contribuir com as finalidades do processo educativo. (Grifo do autor, p. 15)

Essa perspectiva de diálogo está na base de um ambiente de aprendizagem de modelagem matemática, o qual pressupõe a construção coletiva do conhecimento matemático em grupos de discussão.

Neste trabalho nos valemos da observação dos "percursos discursivos" na concepção de Barbosa (2007) e de Barbosa e Santos (2007), tendo em conta que essa reconhece, como elemento essencial para dar suporte à intervenção do professor, as discussões geradas no espaço de interação de um ambiente de aprendizagem na perspectiva de modelagem. Sendo assim, buscamos indícios da natureza da ação pedagógica efetivada em uma situação específica, a qual será explicitada a seguir.

\section{Apresentação dos dados}

Conforme já pontuado, a análise partirá das discussões de uma professora com seus alunos, durante um episódio de sala de aula de uma turma de quinto ano envolvida no desenvolvimento de um projeto na perspectiva de modelagem. O foco de nossa análise é a ação pedagógica ${ }^{10}$ empreendida. Para tanto, tomaremos os "percursos discursivos" em momentos específicos do desenvolvimento do projeto, nos quais a professora intervém na apresentação dos alunos, buscando instigá-los para construir os conhecimentos e os raciocínios envolvidos na situação analisada. Consideramos conveniente apresentar a proposta de trabalho da professora, para situar o leitor no ambiente de aprendizagem que originou a ação aqui apresentada e discutida em seguida.

Os dados serão analisados sob a ótica do construto "percursos discursivos" de Barbosa (2006) e dos "estilos de intervenção" apresentados por Blum e Ferri (2009). Essa escolha se dá em função de considerarmos que observar o fazer pedagógico no desenvolvimento da atividade, sob essas duas perspectivas, pode fornecer elementos para ampliar a compreensão sobre a intervenção pedagógica em um ambiente de aprendizagem na perspectiva de modelagem matemática.

\section{O projeto "Brincadeiras"}

O projeto idealizado pela professora Silvia tinha como objetivo investigar qual a brincadeira mais popular entre os estudantes das quatro turmas de quinto ano (A, B, C e D) de uma escola municipal. Ele foi desenvolvido com seus alunos do quinto ano $\mathrm{C}$, que atuaram como pesquisadores e também como sujeitos da pesquisa. Conforme a professora, o tema foi escolhido pelos alunos (por eleição), dentre outros de interesse manifestado por eles.

\footnotetext{
${ }^{10}$ Diz respeito à interação que ocorre entre duas ou mais pessoas a partir de uma perspectiva reflexiva, metódica e sistemática.
} 
DOl: http://dx.doi.org/10.20396/zet.v25i2.8648493

O trabalho seria feito em grupos de cinco alunos, sendo o projeto dividido em dois momentos.

No primeiro, seria feita uma votação para escolher a brincadeira preferida da própria turma, e cada grupo deveria fazer um texto instrucional para cada uma das três brincadeiras mais votadas na turma. Ao final, esse material seria reescrito coletivamente, gerando, para cada brincadeira, um texto que explicaria suas regras e serviria de base para a apresentação que os alunos fariam nas salas das outras três turmas de quinto ano da escola.

No segundo momento, três das turmas de quinto ano (A, B e D) seriam os sujeitos da pesquisa, cujo objetivo seria descobrir qual a brincadeira preferida dos estudantes das turmas A, B, C e D de quinto ano da escola. Os dados seriam coletados por meio de entrevista, e os alunos pesquisadores (do quinto ano $\mathrm{C}$ ) fariam a análise e a comunicação dos resultados para sua própria turma (socialização e discussão) e depois para os colegas das outras turmas. Por fim, eles iriam ao pátio da escola se entreter com a brincadeira mais votada.

O projeto proposto apresenta as características de um ambiente de aprendizagem pautado na inquirição, com valorização da construção autônoma dos estudantes, convergindo com a perspectiva de modelagem (Barbosa, 2001; Mendonça, 1993; Mendonça \& Lopes, 2011b). As ações empreendidas pelos sujeitos envolvidos no seu desenvolvimento, professor e alunos, serão objeto de análise deste trabalho.

\section{Os percursos discursivos na socialização dos modelos construídos pelos alunos}

A seguir, presentamos, inicialmente, a discussão desenvolvida no momento da socialização dos modelos matemáticos ${ }^{11}$ construídos pelas crianças do quinto $\mathrm{C}$ na aula anterior, com os dados coletados nas outras turmas de quintos anos (A, B e D) e expôs os dados coletados na pesquisa.

A dinâmica da socialização dessa aula ocorreu com a apresentação de cada grupo, que foi à frente da turma com dois alunos segurando uma cartolina com seu gráfico ou sua tabela. A partir daí, a professora convidava os outros alunos da classe para falar o que entenderam do modelo exposto, sendo os membros do grupo chamados para esclarecer as dúvidas dos colegas. Quando necessário, a docente intervinha, provocando a reflexão dos estudantes acerca do modelo construído. Durante a apresentação, à medida que os alunos falavam de sua compreensão, a professora sistematizava os conceitos e os procedimentos usados na construção do modelo.

Um recorte de um diálogo está transcrito a seguir. Em meio à transcrição, fazemos apontamentos com foco na intervenção da professora e depois fazemos a análise com base no referencial teórico construído, para evidenciar a intervenção da professora no decorrer do processo de construção dos alunos e observar a influência dessa para a promoção de um ambiente capaz de oportunizar um trabalho autônomo e produtivo.

\footnotetext{
${ }^{11}$ Estamos entendendo modelo matemático como qualquer representação matemática - tabela, gráfico, esquema etc. - de uma situação. O modelo analisado neste trabalho é um gráfico de barras verticais.
} 


\section{Episódio "Socialização dos resultados"}

DOI: http://dx.doi.org/10.20396/zet.v25i2.8648493

Ao expor os resultados de sua investigação, um grupo mostrou um modelo com os dados coletados no quinto ano D. Tais resultados foram revelados por meio de um gráfico de colunas verticais feitas com quadrados de papel colados na cartolina, porém as colunas estavam inclinadas, como revela a Figura 1, a seguir, o que originou uma discussão em que a professora buscou levar os estudantes a perceberem a necessidade da perpendicularidade das colunas em relação ao eixo horizontal.

Prof.a : E esse aqui ó, tá retinho? Tá, Ana? [dirigindo-se a uma aluna participante do grupo que elaborou o modelo].

Ana: Não. Olha aqui ó [apontando para a segunda coluna do gráfico].

Prof. : : David, você acha que é importante estar certinho?

David: Se ficar torto vai ficar inclinado, aí a gente chega no sete [o número em cima da coluna era oito].

Ana: Ele disse que, se ficar torto, acontece o quê?

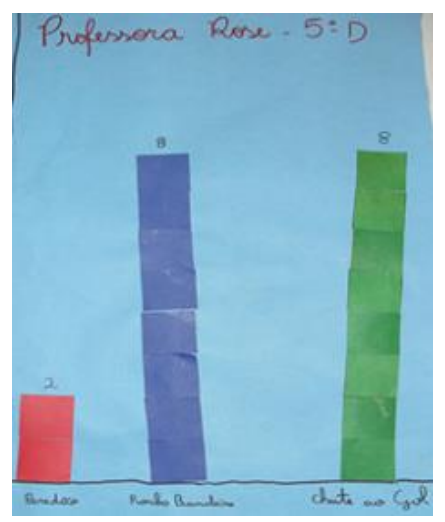

O gráfico de colunas, construído com quadradinhos de papel (representando os votos dos alunos), apresenta as três brincadeiras mais votadas e a quantidade de votos. A partir da origem no eixo horizontal, há três colunas: paredão (2), rouba bandeira (8) e chute a gol (8). O eixo vertical não foi numerado.

Figura 1 - Gráfico das brincadeiras preferidas do quinto ano D

Fonte: Elaborado pelos alunos do grupo 1

David: Se ficar torto só chega no sete [o aluno esclarece, fazendo uma linha na horizontal com a mão, da ponta da coluna até eixo vertical].

Prof.': Ah! Vai ficar inclinada e pode dar um número a menos! [mostrando espanto pela explicação do aluno]. Porque, quando a gente faz, se tem a mesma quantidade, tem que tá na mesma direção, não é? [comparando as duas colunas com o mesmo valor].

A professora se surpreende com a explicação de Davi, mas não explora o termo "inclinado", introduzido por ele.

Ana: Mas, se alguém vem dizer não está assim... [mostrando com a mão a posição vertical] Chute a gol, [apontando uma das colunas] dá pra ler... [indicando o número acima da coluna inclinada]. Não sabe ler, não? [...] Tem o oito, dá pra ver! [Ana coloca a régua sobre as colunas do gráfico e indica o número acima da coluna. Ela tenta mostrar que as colunas tinham o mesmo tamanho, porque tinham o mesmo valor].

Prof. : : Mas e se não tivessem os números?

Ana: Olha! Você percebeu? [mostrando os quadrinhos de papel colado na coluna do gráfico na cartolina] 
DOl: http://dx.doi.org/10.20396/zet.v25i2.8648493

Prof.a: : Mas, às vezes não tem a divisão, a gente só vê a coluna inteira. Aí, não dá pra contar!

$\mathrm{O}$ esclarecimento de Ana referia-se à possibilidade de contar os quadradinhos de papel, os quais foram usados para construir as colunas que representavam os votos dos alunos em cada brincadeira.

Prof. a: Aí, sim, mas e se fosse pintado, como foi feito no papel quadriculado?

Ana: Então... [pensativa] mas eu acho que dá pra entender! Tem como contar!

Prof. : : Não... tem... Mas tem lugar que só está pintado, não é mesmo?

A professora parece perceber a inadequação de sua primeira pergunta, por isso tenta argumentar, mas concorda que, no papel quadriculado, pode-se fazer a contagem. Sua pergunta buscou chamar a atenção da aluna e da classe, que assistia à discussão, para o fato de alguns gráficos não apresentarem valores nas colunas, apenas no eixo vertical numerado, indicando que, nesse caso, as colunas teriam que "ficar em pé", ou seja, ser perpendiculares ao eixo horizontal.

Ana: Mas, professora, deixa eu explicar o que estou querendo dizer! Me dá um giz aí, alguém. [a aluna vai pra lousa representar o seu raciocínio].

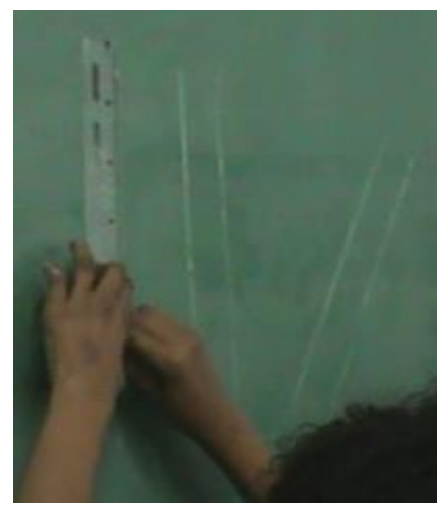

A aluna vai à lousa e desenha, com a régua,
inicialmente duas colunas aparentemente
perpendiculares ao eixo horizontal (imaginário, pois ela
não o desenhou) e uma terceira coluna inclinada para a
direita. Sua representação é diferente do gráfico da
cartolina, pois naquele a coluna do meio também estava
bastante inclinada.

Figura 2 - Representação do raciocínio de Ana

Fonte: Elaborada pela aluna Ana

João: Ô! Tá tortinho!

David: Vai dá pra ver que uma [coluna] vai parecer menor!

Ana: Aqui tá assim... oito, dois, oito [começa escrevendo o número da coluna do meio, depois o da coluna inclinada para a direita e, por último, o da menor, a da esquerda].

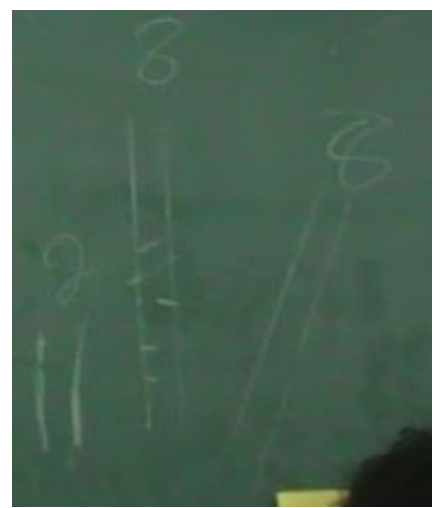

Com suas palavras e com a representação, a aluna tenta explicar que o número acima da coluna é suficiente para a compreensão do gráfico. Ou seja, que as colunas não precisavam ser perpendiculares e, pelo seu registro, nem os eixos seriam necessários.

Figura 3 - Representação do gráfico do grupo 1 
Fonte: Elaborada pela aluna Ana

DOI: http://dx.doi.org/10.20396/zet.v25i2.8648493

Enquanto a aluna desenha, a professora vai até a um armário, pega um livro e apresenta para ela um gráfico de colunas, com a intenção de mostrar o modelo na forma socialmente instituída (coluna contínua).

Prof.: Veja aqui como é! [apontando um gráfico do livro]

Ana: Mas, professora, aqui nesse negócio [mostrando o gráfico do livro] não dá pra contar, [pausa] como não tem essa divisão [referindo-se aos quadradinhos], mas é linha! [O gráfico do livro tinha linhas horizontais que ligavam os valores do eixo vertical às colunas].

Ana: Aqui ó...[fazendo riscos em uma das colunas do gráfico desenhado na lousa, imitando as linhas no gráfico do livro]. Mas, eu tô perguntando assim: aqui tem as linhas, que é assim ó... [traçando as linhas mais fortes alcançando as duas primeiras colunas]. Você tá vendo a linha da lousa? É assim, ó.

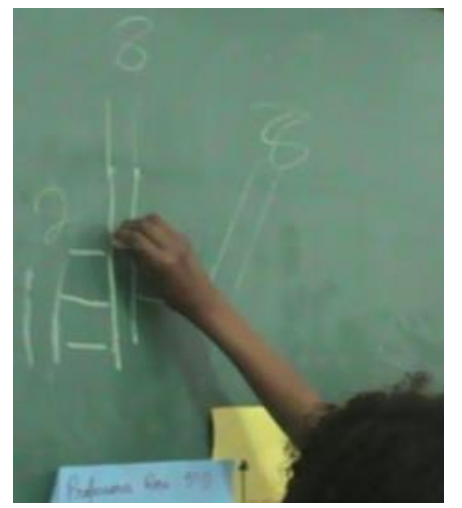

Aqui, a aluna queria convencer seus ouvintes de que as linhas, assim como os quadradinhos, permitem a contagem, mesmo com a falta do número nas colunas, o que possibilita a compreensão do gráfico. Assim, mais uma vez ela justificou as colunas inclinadas em seu gráfico.

Figura 4 - Alteração da representação do gráfico do grupo 1

Fonte: Elaborada pela aluna Ana.

Ana: Mas, essas linhas... [pausa] não valem pra ser... tipo o...[Ana não consegue esclarecer, em palavras, o que desenha na lousa, ou seja, explicar que as linhas permitem contar].

Percebendo a dificuldade da aluna, a professora interfere, buscando ajudá-la.

Prof.': Pra contar?

Ana: $E_{\text {... }}$

Prof. : : Mas o que está torto dá pra contar pela linha?

[A aluna volta à lousa e estica algumas linhas já desenhadas até a terceira coluna, a inclinada].

Ana: A linha vai ficar meio torta também, ó. [A professora deixa a aluna desenvolver seu raciocínio e os outros alunos assistem, interessados]. 
DOl: http://dx.doi.org/10.20396/zet.v25i2.8648493

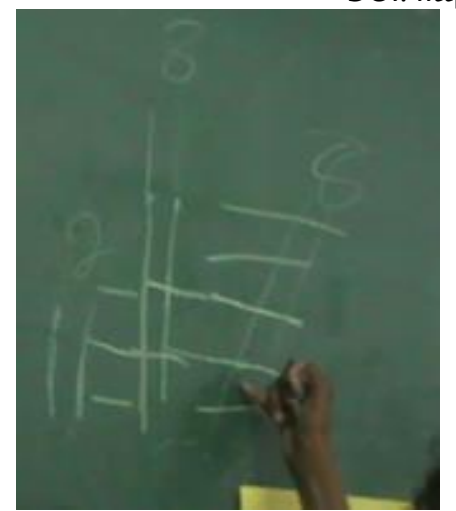

A aluna estica as linhas feitas anteriormente nas duas primeiras colunas até a terceira. Parece ainda não ter se convencido da necessidade de a coluna ser perpendicular ao eixo horizontal. Ela conta os espaços entre as linhas traçadas na coluna inclinada, totalizando seis, pois ela considerou o espaço após a última linha, em cima e embaixo (na foto, o espaço indicado com o dedo era o segundo em sua contagem).

Figura 5 - Alteração da representação do gráfico do grupo 1

Fonte: Elaborada pela aluna Ana

Ana: Aí, vai ficar assim: um, dois, três, quatro, cinco..., seis?

A aluna olha para a professora, incrédula, parece ter compreendido a afirmação inicial do colega de que a coluna inclinada não alcançaria o seu valor " 8 " no eixo vertical.

Prof. : $:$ Deu 8 ?

Ana: Não...

Ana responde sem atribuir importância à imprecisão de sua representação. Mas a professora não interfere, parece lhe bastar a percepção da aluna de que a coluna inclinada não é indicada na construção do gráfico.

Prof.: Mas você entendeu que não pode fazer torto? [A professora se refere à perpendicularidade da coluna no gráfico]

Ana: É... mas, professora, tem esse negócio aqui... [apontando para o gráfico do livro].

Mesmo desapontada, a aluna admite ter compreendido. Ainda assim, ela tenta continuar o diálogo, mas a professora solicita que ela retorne ao seu lugar e chama outro grupo para apresentar o trabalho, dando continuidade à socialização dos trabalhos dos grupos. Esta, no entanto, não será exposta na íntegra aqui, mas alguns discursos pontuais serão apresentados no decorrer da discussão.

\section{Discussões e análise dos dados}

No momento da observação da ação pedagógica em discussão, deparamo-nos com uma situação complexa e um diálogo rico, durante o qual tentamos classificar a intervenção da professora no desenvolvimento da atividade. No entanto, a dinâmica observada nos levou a um questionamento: como é possível caracterizar a ação pedagógica da professora no decorrer do desenvolvimento da atividade de modelagem? Essa inquietação nos direcionou a buscar subsídios nos pressupostos de Blum e Ferri (2009) acerca dos "estilos de intervenção", apoiando-nos nos "percursos discursivos" propostos por Barbosa (2006), observados na sala de aula.

Desse modo, ao observar a dinâmica da aula da Professora "Silvia", não foi possível fazer uma classificação única de sua intervenção no desenvolvimento da atividade, pois vários tipos de mediações foram observados, o que nos faz inferir que a intervenção do professor, ao longo da atividade de modelagem, pode ser compreendida como um conjunto de posturas que se situam entre dois extremos: de um lado, está a "intervenção diretiva", a 
DOl: http://dx.doi.org/10.20396/zet.v25i2.8648493

qual caracteriza a ação pedagógica que direciona o processo de construção dos alunos, indicando estratégias, conceitos e ações; e do outro, a "intervenção estratégica", na qual o estímulo ao raciocínio, à reflexão e à ação dá suporte à ação pedagógica. Assim, no decorrer do desenvolvimento de atividades de modelagem, a ação do professor não é apenas diretiva ou estratégica. Ela varia ao longo do processo, indo de um extremo a outro. No entanto, entre esses dois extremos, uma infinidade de outras posturas pode ocorrer, de acordo com as necessidades dos alunos e com os objetivos da atividade. A imagem que segue, no Quadro 1, mostra essa ideia.

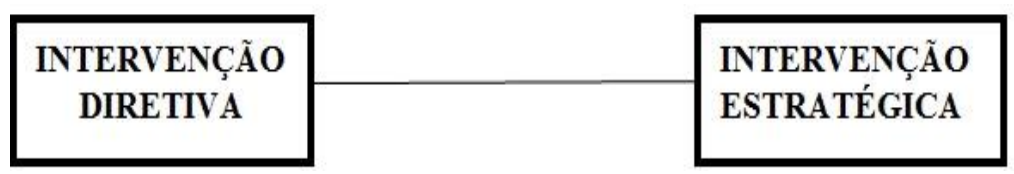

Figura 6 - Postura do professor no desenvolvimento de atividades de modelagem

Fonte: Mendonça (2015, p. 193)

A compreensão dessa dinâmica nos possibilitou construir encaminhamentos para analisar a ação pedagógica em cada situação específica, observando o contexto em que ela ocorria. De modo geral, no desenvolvimento do projeto da professora Silvia, os "percursos discursivos" permitiram observar a predominância do estilo de "intervenção estratégica" em sua ação pedagógica, já que essa, na maior parte das vezes, foi questionadora. Ademais, as ações da docente foram intencionais, no sentido de levar os alunos a perceberem conhecimentos específicos em cada momento da investigação empreendida pelos grupos. Outra evidência dessa postura é a observação do "estilo de pensamento" da aluna Ana, o estilo visual, o qual foi expresso nos registros apresentados na lousa por ela no episódio analisado e que serviu de base para estratégias de intervenção da professora, como a comparação com um modelo do livro didático e a exploração do próprio modelo da aluna, durante o diálogo que se estabelece entre elas.

A professora também se valeu do seu conhecimento sobre características comportamentais da aluna, o que permitiu elaborar perguntas pertinentes e instigadoras em um diálogo construtivo, que ampliou as possibilidades de construção de conhecimentos sobre a elaboração de gráficos de barras verticais. Essa percepção pode ser observada na fala da professora: "A aluna Ana gosta de fazer prevalecer suas ideias. É difícil convencê-la de qualquer coisa que vai contra o que ela pensa!'. O fato de valorizar e deixar fluir as ideias da aluna foi determinante para que essa construísse seu raciocínio, percebendo a importância da perpendicularidade da coluna.

Já em outra situação, ao iniciar o diálogo apresentado anteriormente, a professora fez o questionamento: “E esse aqui ó, tá retinho?”. Com essa pergunta, ela acabou direcionando as respostas dos alunos, mesmo com uma postura questionadora. Talvez fosse mais estratégico instigar os alunos a fazer comparação daquele gráfico com outros já apresentados e esperar que eles percebessem as diferenças. Esse processo os levaria a mobilizar os conhecimentos em relação ao gráfico de barras para fazer relações entre os diversos gráficos.

Essa atitude foi observada em uma discussão sobre a graduação do eixo do gráfico de outro grupo, quando a professora buscou fazer os alunos compreenderem a importância de marcar o zero na intersecção dos eixos, já que esse grupo não o havia marcado em seu 
DOl: http://dx.doi.org/10.20396/zet.v25i2.8648493

gráfico. Nesse caso, ela instigou a comparação com outro gráfico, no qual o zero estava marcado. Para isso, ela fez a pergunta: "Qual é a diferença aqui e aqui? Quem sabe me dizer?". Naquele momento ela investiu em levar os alunos a perceberem a diferença entre os eixos dos dois gráficos para a exploração da graduação de seus eixos.

De todo modo, nos parece natural esse ir e vir, em maior ou menor grau, entre o estilo diretivo e estratégico de intervenção, considerando a complexidade da sala de aula, as necessidades dos alunos, os objetivos da atividade e, claro, a inexperiência da professora tanto com a modelagem matemática, como com a abordagem da Estatística por meio de um projeto. Como é possível observar, é notória a predominância da intervenção estratégica no decorrer do processo, em que se observa uma postura reflexiva e dialógica, e uma visão de educação comprometida com a aprendizagem e o desenvolvimento dos estudantes de forma geral.

No que se refere às discussões presentes no decorrer do diálogo, há predominância das "discussões matemáticas" (ideia de perpendicularidade) e das técnicas (procedimentos para a construção do gráfico de barras verticais e adequação do modelo construído pelo grupo ao socialmente aceito), o que indica empenho no desenvolvimento dos conceitos matemáticos. As "discussões reflexivas", por sua vez, permearam o debate, o que ocorre, por exemplo, quando a docente chama a atenção dos alunos para a situação de não haver votos em uma brincadeira. Apesar de, nos diálogos apresentados, aparecerem poucas relações do modelo construído com a situação real que representa, característica desse tipo de discussão, conforme Barbosa (2006), elas são frequentes na etapa final do projeto, por exemplo, quando ocorre a generalização dos resultados observados nas três turmas pesquisadas para a definição da brincadeira preferida dos quintos anos, sem que os resultados da própria turma tenham sido contabilizados.

É possível observar o esforço da professora em validar o modelo socialmente aceito no primeiro diálogo, sem desvalorizar a produção do grupo. Nesse processo, por vezes, ela encontrou dificuldade em argumentar para justificar a necessidade da perpendicularidade das colunas do gráfico. É visível também certa ansiedade para o cumprimento do currículo prescrito, quando a discussão é encerrada pela docente mesmo com a aluna querendo continuá-la. Ainda assim, a professora possibilitou à estudante construir seu raciocínio e compreender as ideias em questão. De todo esse processo ressalta a importância da dinâmica reflexiva e dialógica do ambiente oportunizado pela professora para levar os alunos à compreensão das ideias sobre a construção do modelo matemático em foco.

\section{Considerações finais}

A investigação efetivada possibilita-nos inferir que, no momento do desenvolvimento da atividade de modelagem, os dois estilos de intervenção discutidos por Blum e Ferri (2009), de fato, podem ocorrer - além de outros, entre esses dois extremos. Ademais, percebemos que, nesse processo, às vezes os "percursos discursivos" dos alunos não são ouvidos nem seus "estilos de pensamento" são captados. E isso ocorre por conta da própria dinâmica da sala de aula e de outras questões, como o cumprimento do currículo escolar ou do tempo Zetetiké, Campinas, SP, v.25, n.2, maio/ago.2017, p.305-323. 
DOI: http://dx.doi.org/10.20396/zet.v25i2.8648493

destinado à atividade, fatores que, muitas vezes, impedem uma intervenção estratégica que leve os alunos a buscar soluções de forma autônoma, de acordo com os pressupostos da modelagem na Educação Matemática (Barbosa, 2001; Blum \& Ferri, 2009).

Com isso, ponderamos que a prática pedagógica com a modelagem matemática, em função de sua dinâmica aberta, demanda uma atitude reflexiva, comprometida e ativa e reflexiva do professor. Essas atitudes são essenciais para que ele intervenha de modo a contribuir para o desenvolvimento de conceitos, procedimentos e atitudes específicas dos estudantes, tendo em conta, no entanto, sua autonomia. Esse processo contínuo com a dinâmica da modelagem, como é possível concluir, é construído ao longo do tempo, com a promoção de atividades dessa natureza na rotina da sala de aula. Ele permitirá construir gradativamente uma cultura investigativa na sala de aula, a qual poderá ampliar a cada dia o repertório de estratégias de intervenção do docente para contribuir cada vez mais com a formação dos estudantes.

\section{Referências}

Arnaus, R. (1999). La formación del profesorado: un encuentro comprometido con la complexidad educativa. In J. F. Rasco, J. B. Ruiz, \& A. P. Gomez (Orgs.), Desarrollo profesional del docente: política, investigación y práctica (pp. 559-635). Madrid: Akal.

Arteaga, P., Batanero, C. R., Cañadas G. R., \& Contreras, M. (2013, fevereiro). Prospective primary school teachers' errors in building statistical graphs. In Anais of $8^{\text {th }}$ Congress of European Research in Mathematics Education (pp. 1-10). Antalya, Turkey: CERME.

Barbosa, J. C. (2001). Modelagem na educação matemática: contribuições para o debate teórico. In Anais da 24a. Reunião Anual da ANPED (pp. 1-15). Caxambu: ANPED.

Barbosa, J. C. (2004). As relações dos professores com a Modelagem. In Anais do 8. Encontro Nacional de Educação Matemática (pp. 1-17). Recife: SBEM. CD-ROM.

Barbosa, J. C. (2006). A dinâmica das discussões dos alunos no ambiente de modelagem matemática. In Anais do 3. ${ }^{o}$ Seminário Internacional de Pesquisa em Educação Matemática (pp. 1-12). Águas de Lindóia: SBEM. CD-ROM.

Barbosa, J. C. (2007). A prática dos alunos no ambiente de modelagem matemática: o esboço de um framework. In J. C. Barbosa, A. Caldeira \& J. Araújo (Orgs.), Modelagem matemática na educação matemática brasileira: pesquisas e práticas educacionais (pp. 161-74). Recife: SBEM.

Barbosa, J. C., \& Santos, M. A. (2007). Modelagem matemática: perspectivas e discussões. In Anais do 9 Encontro Nacional de Educação Matemática (pp. 1-12). Recife: SBEM.

Bassanezi, R. C. (2004). Ensino-aprendizagem com modelagem matemática (2a ed.). São Paulo: Contexto. 
DOI: http://dx.doi.org/10.20396/zet.v25i2.8648493

Batanero, C. (2009). Retos para la formación estadística de los profesores. In Actas do 2 Encontro de probabilidade e Estatistica na escola (pp. 7-21). Braga: Universidade do Minho.

Biembengut, M. S., \& Vieira, E. M. (2013). Mathematical modeling in teacher education courses: style of thought in the international community. ICTMA. In Proceedings of the $8^{\text {th }}$ Congress of European Research in Mathematics Education. Antalya: Cerme. Retirado em 22 de janeiro, 2017, de: <http://cerme8.metu.edu.tr/wgpapers/WG6/WG6_Salett_Biembengut.pdf.>.

Blum, W., \& Ferri, R. B. (2009). Mathematical modelling: can it be taught and learnt? Journal of Mathematical Modeling and Application, 1(1), 45-58.

Chaves, M. I. A. (2012). Percepções de professores sobre repercussões de suas experiências com modelagem matemática. Tese de Doutorado em Educação em Ciências e Matemáticas. Belém: Instituto de Educação Matemática e Científica, Universidade Federal do Pará.

Chick, H., \& Pierce, R. (2010). Helping teachers to make effective use of real-world examples in Statistics. In Proceedings of the $8^{\text {th }}$ International Conference on Teaching Statistics (pp. 1-5). Ljubljana: IASE.

Ferri, R. B. (2006). Theoretical and empirical differentiations of phases in the modeling process. ZDM, 38(2), 86-95.

Ferri, R. B. (2008). Insight into teacher's unconscious behavior while dealing whit mathematical modeling problems and implications for teacher education. In Anais do Symposium on the Occasion of the $10^{\text {th }}$ Anniversary of ICMI (pp. 1-5). Roma: ICMI.

Garnica, A. V. M. (2004). História oral e educação matemática. In: M. C. Borba \& J. L. Araújo (Orgs.), Pesquisa qualitativa em Educação Matemática (pp. 77-98). Belo Horizonte: Autêntica.

Kaiser, G., \& Sriraman, B. (2006). A global survey of international perspectives on modelling in mathematics education. Zentralblatt für Didaktik der Mathematik, 38(3), 302-310.

Libâneo, J. C. (2010). O ensino da didática, das metodologias específicas e dos conteúdos específicos do ensino fundamental nos currículos dos cursos de Pedagogia. Revista Brasileira de Estudos Pedagógicos, 91(229), 562-583. Retirado em 22 de janeiro, 2017, de: <http://rbep.inep.gov.br/index.php/rbep/article/view/630 .

Lopes, C. E. (2003). O conhecimento profissional dos professores e suas relações com estatística e probabilidade na educação infantil. Tese de Doutorado em Educação. Campinas: Universidade Estadual de Campinas.

Mendonça, L. O. (2008). A Educação Estatística em um ambiente de modelagem matemática no ensino médio. Dissertação de Mestrado em Ensino de Ciências e Matemática. São Paulo: Universidade Cruzeiro do Sul. 
DOI: http://dx.doi.org/10.20396/zet.v25i2.8648493

Mendonça, L. O. (2015). Reflexões e ações de professores sobre modelagem matemática na Educação Estatística em um grupo colaborativo. Tese de Doutorado em Ensino de Ciências e Matemática. São Paulo: Universidade Cruzeiro do Sul.

Mendonça, L. O., \& Lopes, C. E. (2011 a). A ação pedagógica em ambientes de modelagem matemática: uma discussão a partir da própria prática. In Anais da 7 Conferência Nacional sobre Modelagem na Educação Matemática (pp. 1-18). Belém: UFPA.

Mendonça, L. O., \& Lopes, C. E. (2011b). Modelagem matemática: um ambiente de aprendizagem para a implementação da Educação Estatística no Ensino Médio. Bolema, 24(40), 701-724.

Mendonça, M. C. (1993). Problematização: um caminho a ser percorrido em Educação Matemática. Tese de Doutorado em Educação. Camapinas: Universidade Estadual de Campinas.

Oliveira, A. M. P. (2010). Modelagem matemática e as tensões nos discursos dos Professores. Tese de Doutorado em Ensino, Filosofia e História das Ciências. Salvador: Universidade Federal da Bahia e Universidade Estadual de Feira de Santana.

Silva, D. K., \& Dalto, J. O. (2011). Modelagem matemática na formação de professores: compartilhando uma experiência. In L. M. W. Almeida, J. L. Araújo \& E. Bisognin (Orgs.), Práticas de modelagem matemática na Educação Matemática (pp. 181-200). Londrina: Eduel.

Síveres, L. (2016). O diálogo na educação: uma relação entre o dialógico e a dialogicidade. In L. Síveres (Org.), Diálogo: um princípio pedagógico (pp.15-30). Brasília: Liber Livro.

Skovsmose, O. (1990). Reflective knowledge: its relation to the mathematical modelling process. International Journal of Mathematical Education in Science and Technology, 21(5), 765-779.

Wild, C., \& Pfannkuch, M. (1999). Statistical thinking in empirical enquiry. International Statistical Review, 67(3), 223-65. Retirado em 22 de janeiro, 2017, de: http://iaseweb.org/documents/intstatreview/99.Wild.Pfannkuch.pdf.

Zaslavsky, A. (2017). Ação pedagógica, ação comunicativa e didática. Conjectura: Filos. Educ., 22(1), 69-81. Retirado em agosto, 2017, de: <file://C:/Users/Luzinete/Downloads/4435-18674-1-PB.pdf>. 